\title{
Ograniczenia funkcjonalne związane z dolegliwościami bólowymi odcinka lędźwiowo-krzyżowego kręgosłupa wśród kobiet ciężarnych
}

\section{Functional limitations associated with lumbosacral spine pain in pregnant women}

\author{
Magdalena Brylewska-Pinda1, Ewa Kemicer-Chmielewska², Joanna Pierzak-Sominka33, Hanna Mosiejczuk ${ }^{4}$ \\ ${ }^{1}$ Koło Naukowe „Kinezis” przy Samodzielnej Pracowni Rehabilitacji Medycznej Pomorskiego Uniwersytetu Medycznego w Szczecinie \\ ul Żołnierska 54, 71-210, Szczecin \\ Opiekun: dr n. med. Iwona Rotter
}

2 Katedra i Zakład Zdrowia Publicznego Pomorskiego Uniwersytetu Medycznego w Szczecinie

ul Żołnierska 48, 71-210, Szczecin

Kierownik: prof. dr hab. n. zdr. Beata Karakiewicz

${ }^{3}$ Zakład Epidemiologii i Zarządzania Pomorskiego Uniwersytetu Medycznego w Szczecinie

ul Żołnierska 48, 71-210, Szczecin

Kierownik: dr hab. n. med., prof. PUM Maria Gańczak

4 Samodzielna Pracownia Rehabilitacji Medycznej Pomorskiego Uniwersytetu Medycznego w Szczecinie

ul Żołnierska 54, 71-210, Szczecin

Kierownik: dr n. med. Iwona Rotter

\begin{abstract}
Introduction: Lower back pain affects most pregnant women. Pain is often associated with varying degrees of functional limitations, causing a problem for pregnant women in the performance of many everyday activities.

The aim of the study was to assess the extent to which lumbosacral spine pain caused limitations in the daily functioning of pregnant women, and the relationship between reported restrictions and analysed variables.

Material and methods: The study was conducted in the city of Szczecin in Poland among 81 pregnant women. Data were collected using a standardized Oswestry questionnaire survey (The
\end{abstract}

\section{STRESZCZENIE}

Wstęp: Bóle dolnego odcinka kręgosłupa dotyczą większości kobiet w ciąży. Na skutek dolegliwości bólowych często pojawiają się ograniczenia funkcjonalne różnego stopnia sprawiające kłopot przy wykonywaniu wielu codziennych czynności.

Celem pracy była ocena stopnia dolegliwości bólowych odcinka lędźwiowo-krzyżowego kręgosłupa oraz określenie zależności badanych ograniczeń od zmiennych kontrolowanych.

Materiał i metody: Badanie przeprowadzono na terenie miasta Szczecina wśród 81 kobiet ciężarnych. Posłużono się standaryzowanym kwestionariuszem ankiety Oswestry (The Oswestry Low Back Pain Disability Questionnaire). Do weryfikacji
Oswestry Lower Back Pain Disability Questionnaire). Results were analysed using the $\chi^{2}$ test of independence. The significance level was adopted at $\mathrm{p}<0.05$.

Results: The majority of women pregnant for the second time $(\mathrm{n}=38)$ had mild disability. The relationship between the degree of disability and the order of pregnancies was statistically significant $\left(\chi^{2}=40.457, \mathrm{p}=0.0000000085\right)$.

Conclusions: The majority of pregnant women had minor functional limitations due to pain in the lumbosacral spine region. The degree of functional limitations depends on the trimester of pregnancy and the order of pregnancies.

Keywords: pregnant women, back pain, mobility limitation.

\section{WSTĘP}

Bóle dolnego odcinka kręgosłupa dotyczą większości kobiet w ciąży. Ciąża to okres, w którym dochodzi do szeregu zmian w układzie czynnościowym, hormonalnym i strukturalnym kobiet. Zmianie ulega postawa ciała wynikająca z przeniesienia środka ciężkości i wzrostu masy ciała, co wpływa

statystycznej otrzymanych wyników badań wykorzystano test niezależności $\chi^{2}$. Przyjęto poziom istotności $p<0,05$.

Wyniki: U większości kobiet będących po raz drugi w ciąży ( $\mathrm{n}=38)$ stwierdzono mierną niepełnosprawność. Zależność pomiędzy stopniem niepełnosprawności a kolejnością ciąż była statystycznie istotna $\left(\chi^{2}=40,457 ; p=0,0000000085\right)$.

Wnioski: U większości kobiet ciężarnych zaobserwowano ograniczenia funkcjonalne spowodowane dolegliwościami bólowymi odcinka lędźwiowo-krzyżowego kręgosłupa w stopnie miernym. Stopień ograniczeń funkcjonalnych zależny jest od trymestru ciąży i kolejności ciąż.

Słowa kluczowe: kobiety w ciąży, zespół bólowy kręgosłupa, ograniczenie poruszania się. 
Na skutek dolegliwości bólowych często pojawiają się ograniczenia funkcjonalne różnego stopnia sprawiające kobietom w ciąży kłopot przy wykonywaniu wielu czynności dnia codziennego [6].

Celem pracy była ocena, w jakim stopniu dolegliwości bólowe odcinka lędźwiowo-krzyżowego kręgosłupa powodowały ograniczenia w codziennym funkcjonowaniu kobiet ciężarnych oraz określenie zależności badanych ograniczeń od zmiennych kontrolowanych, takich jak: wiek, trymestr ciąży, kolejność ciąż, uczestnictwo w zajęciach organizowanych przez szkoły rodzenia.

\section{MATERIA I I METODY}

Badanie przeprowadzono na terenie miasta Szczecina wśród 81 kobiet ciężarnych w przedziałach wiekowych: 18-25 lat (20,99\%); 26-30 lat (35,80\%); 31-35 lat (29,63\%); powyżej 35 lat (13,58\%), u których występują dolegliwości bólowe odcinka lędźwiowo-krzyżowego kręgosłupa. Większość z nich była w III trymestrze ciąży $(81,48 \%)$. W grupie badanej najliczniejszą grupę $(61,73 \%)$ stanowiły kobiety będące w ciąży po raz drugi. W badaniach posłużono się standaryzowanym kwestionariuszem ankiety Oswestry (Oswestry Disability Index - ODI), za pomocą którego ocenia się 10 podstawowych czynności: intensywność bólu, podnoszenie przedmiotów, siedzenie, podróżowanie, pielęgnacja (np. mycie, ubieranie się), chodzenie, stanie, życie towarzyskie, spanie, wypoczynek. Każda z czynności posiadała 6 możliwych odpowiedzi punktowanych w skali 0-5, gdzie o oznaczało brak ograniczeń przy wykonywaniu wybranej czynności, a 5 całkowitą niezdolność do jej wykonywania. Punkty uzyskane przez respondenta w każdej części ankiety były sumowane. Przy braku ograniczeń funkcjonalnych liczba wynosiła 0, a przy ograniczeniach funkcjonalnych powyżej o. Im większa liczba punktów, tym większe ograniczenia. Następnie sumę punktów przedstawiono w procentach, obliczając w ten sposób indeks niepełnosprawności ODI (tab. 1).

Ponadto poproszono ankietowanych o wypełnienie autorskiego kwestionariusza ankiety. Zawarte w nim pytania miały pozwolić na określenie przyczyny występowania ograniczeń w wykonywaniu czynności dnia codziennego. Do weryfikacji statystycznej otrzymanych wyników badań wykorzystano test niezależności $\chi^{2}$. Przyjęto poziom istotności $p<0,05$.

\section{WYNIKI}

Wyniki poszczególnych badań przedstawiono w tabelach 2-5.

W tabeli 2 zwrócono uwagę na stopień ograniczeń funkcjonalnych u kobiet biorących udział w zajęciach organizowanych przez szkoły rodzenia, u których stwierdzono niepełnosprawność w stopniu miernym. Testy statystyczne nie wykazały

TABELA 1. Interpretacja wskaźnika ODI stosowana w kwestionariuszu Oswestry [7]

\begin{tabular}{|c|c|}
\hline $\begin{array}{c}\text { Wskaźnik } \\
\text { ODI }\end{array}$ & Stopień niepełnosprawności \\
\hline $0-20 \%$ & $\begin{array}{l}\text { Brak niepełnosprawności. } \\
\text { Ciężarna może poradzić sobie z większością } \\
\text { codziennych czynności. }\end{array}$ \\
\hline $21-40 \%$ & $\begin{array}{l}\text { Niewielka niepełnosprawność. } \\
\text { Ciężarna może doświadczyć więcej bólu, ma problemy } \\
\text { z siedzeniem, podnoszeniem się i staniem. Podróże } \\
\text { i życie towarzyskie są utrudnione. }\end{array}$ \\
\hline $41-60 \%$ & $\begin{array}{l}\text { Mierna niepełnosprawność. } \\
\text { Ból jest poważnym problemem kobiety ciężarnej. Może } \\
\text { się ona również zmagać z poważnymi problemami } \\
\text { w podróży, przy higienie osobistej, w życiu towarzyskim } \\
\text { i podczas snu. }\end{array}$ \\
\hline $61-80 \%$ & $\begin{array}{l}\text { Poważna niepełnosprawność. } \\
\text { Ból pleców wpływa negatywnie na wszystkie aspekty } \\
\text { życia codziennego kobiety ciężarnej. }\end{array}$ \\
\hline $81-100 \%$ & $\begin{array}{l}\text { Całkowita niepełnosprawność. } \\
\text { Kobieta jest zazwyczaj przykuta do łóżka i potrzebuje } \\
\text { pomocy osób trzecich przy wykonywaniu czynności. }\end{array}$ \\
\hline
\end{tabular}

wskaźnik ODI - wskaźnik niepełnosprawności Oswetry

TABELA 2. Ocena stopnia niepełnosprawności u kobiet ciężarnych względem uczestnictwa w zajęciach organizowanych przez szkoły rodzenia

\begin{tabular}{lccc}
\multicolumn{1}{c}{$\begin{array}{c}\text { Stopień } \\
\text { niepetnosprawności }\end{array}$} & \multicolumn{3}{c}{$\begin{array}{c}\text { Uczestnictwo w zajęciach } \\
\text { organizowanych przez szkoły } \\
\text { rodzenia }\end{array}$} \\
\cline { 2 - 4 } & $\begin{array}{c}\text { tak } \\
\mathbf{n}(\%)\end{array}$ & $\begin{array}{c}\text { nie } \\
\mathbf{n}(\%)\end{array}$ & $\begin{array}{c}\text { suma } \\
\mathbf{n}(\%)\end{array}$ \\
\hline Brak niepełnosprawności & $3(3,7)$ & $3(3,7)$ \\
\hline $\begin{array}{l}\text { Niewielka } \\
\text { niepełnosprawność }\end{array}$ & $25(30,86)$ & $25(30,86)$ \\
\hline Mierna niepełnosprawność & $8(9,88)$ & $39(48,15)$ & $47(58,03)$ \\
\hline Poważna niepełnosprawność & & $5(6,18)$ & $5(6,18)$ \\
\hline Całkowita & & $1(1,23)$ & $1(1,23)$ \\
niepełnosprawność & $8(9,88)$ & $73(90,12)$ & $81(100)$ \\
\hline Suma & &
\end{tabular}

TABELA 3. Ocena stopnia niepełnosprawności u kobiet ciężarnych względem kolejności ciąż

\begin{tabular}{|c|c|c|c|c|c|}
\hline \multirow{2}{*}{$\begin{array}{c}\text { Stopień } \\
\text { niepełnosprawności }\end{array}$} & \multicolumn{5}{|c|}{ Kolejność ciąż } \\
\hline & $\begin{array}{c}1 \\
n(\%)\end{array}$ & $\begin{array}{c}2 \\
n(\%)\end{array}$ & $\begin{array}{c}3 \\
n(\%)\end{array}$ & $\begin{array}{c}>3 \\
n(\%)\end{array}$ & $\begin{array}{l}\text { suma } \\
\mathrm{n}(\%)\end{array}$ \\
\hline Niewielka niepełnosprawność & $13(16,06)$ & $12(14,81)$ & & & $25(30,87)$ \\
\hline Mierna niepełnosprawność & & $38(46,91)$ & $9(11,11)$ & & $47(58,02)$ \\
\hline Poważna niepełnosprawność & & & $5(6,18)$ & & $5(6,18)$ \\
\hline Całkowita niepełnosprawność & & & $1(1,23)$ & & $1(1,23)$ \\
\hline Suma & $16(19,76)$ & $50(61,72)$ & $15(18,52)$ & & $81(100)$ \\
\hline
\end{tabular}


TABELA 4. Ocena stopnia niepełnosprawności u kobiet ciężarnych względem trymestru ciąży

\begin{tabular}{|c|c|c|c|c|}
\hline \multirow{2}{*}{$\begin{array}{c}\text { Stopień } \\
\text { niepełnosprawności }\end{array}$} & \multicolumn{4}{|c|}{ Trymestr ciąży } \\
\hline & $\begin{array}{c}\text { I } \\
\text { n (\%) }\end{array}$ & $\begin{array}{l}\text { II } \\
n(\%)\end{array}$ & $\begin{array}{c}\text { III } \\
n(\%)\end{array}$ & $\begin{array}{l}\text { suma } \\
\mathrm{n}(\%)\end{array}$ \\
\hline $\begin{array}{l}\text { Brak } \\
\text { niepełnosprawności }\end{array}$ & & $3(3,7)$ & & $3(3,7)$ \\
\hline $\begin{array}{l}\text { Niewielka } \\
\text { niepełnosprawność }\end{array}$ & & $12(14,81)$ & $13(16,06)$ & $25(30,87)$ \\
\hline $\begin{array}{l}\text { Mierna } \\
\text { niepełnosprawność }\end{array}$ & & & $47(58,02)$ & $47(58,02)$ \\
\hline $\begin{array}{l}\text { Poważna } \\
\text { niepełnosprawność }\end{array}$ & & & $5(6,18)$ & $5(6,18)$ \\
\hline $\begin{array}{l}\text { Całkowita } \\
\text { niepełnosprawność }\end{array}$ & & & $1(1,23)$ & $1(1,23)$ \\
\hline Suma & $0(0)$ & $15(18,51)$ & $66(81,49)$ & $81(100)$ \\
\hline
\end{tabular}

zależności pomiędzy uczestnictwem w zajęciach szkoły rodzenia a stopniem niepełnosprawności $\left(\chi^{2}=1,961 ; p=0,742988\right)$.

Analizując przedstawione w tabeli 3 wyniki badań, można zauważyć, że u większości kobiet będących po raz drugi w ciąży (n = 38) stwierdzono mierną niepełnosprawność. Zależność pomiędzy tymi zmiennymi była statystycznie istotna $\left(\chi^{2}=40,457 ; p=0,0000000085\right)$.

W tabeli 4 przedstawiono wyniki oceny stopnia niepełnosprawności w zależności od trymestru ciąży. U większości kobiet będących w III trymestrze stwierdzono niepełnosprawność mierną. Analiza statystyczna wykazała, że trymestr ciąży warunkuje stopień niepełnosprawności $\left(\chi^{2}=38,831\right.$; $\mathrm{p}=0,0000000037$.

Wyniki badania przeprowadzonego wśród kobiet ciężarnych z uwzględnieniem wieku (tab. 5) poddano analizie statystycznej i stwierdzono, że wiek nie warunkuje stopnia niepełnosprawności spowodowanej dolegliwościami bólowymi dolnego odcinka kręgosłupa $\left(\chi^{2}=0,319937 ; p=0,5716456\right)$.

\section{DYSKUSJA}

Ciąża może być przyczyną bólów okolicy lędźwiowo-krzyżowej i uznawana jest za istotny problem zdrowotny kobiety ciężarnej [8]. Przeprowadzone badania Boch-Kmieciak i wsp. dotyczące zmian cech somatycznych i krzywizn kręgosłupa podczas ciąży wśród badanej grupy 30 kobiet w przedziale wiekowym 20-35 lat potwierdzają, że zmiany zachodzące w obrębie organizmu kobiety są przyczyną dolegliwości bólowych kręgosłupa [1]. Chitryniewicz i Kulis na podstawie przeprowadzonych badań 85 ciężarnych stwierdzili, że u większości z nich (71,7\%) ból kręgosłupa powoduje niewielkie ograniczenia w wykonywaniu czynności życia codziennego [9].

Z badań własnych wynika, że niewielkie ograniczenie funkcjonalne spowodowane dolegliwościami bólowymi okolicy lędźwiowo-krzyżowej kręgosłupa odczuwa 30,86\% kobiet, natomiast u 58,02\% ból wywołuje znacznie większe ograniczenia funkcjonalne określone miernym stopniem niepełnosprawności. Najwięcej kobiet (51,85\%), u których stwierdzono mierny stopień niepełnosprawności, było w wieku 26-35 lat i w III trymestrze ciąży. To, że ból jest silniejszy i częściej odczuwany w III trymestrze ciąży potwierdzają badania Majchrzyckiego i wsp. [10]. Należy również zwrócić uwagę na wyniki badań uzyskane przez tych autorów, według których dolegliwości bólowe kręgosłupa występują u kobiet ciężarnych po raz pierwszy w II trymestrze ciąży, ale są mniej uciążliwe niż w III trymestrze. Zbieżne z tymi wynikami są wyniki badań własnych. Zdaniem Majchrzyckiego i wsp. ból kręgosłupa nasila się wraz z kolejną ciążą [10]. Nie potwierdzają tego wyniki badań przeprowadzone przez Rogalę wśród 100 kobiet ciężarnych, wg których kolejność ciąż nie wpływa na nasilenie dolegliwości bólowych kręgosłupa [6]. Natomiast wyniki badań własnych poddane analizie statystycznej wykazały istotną statystycznie zależność pomiędzy stopniem niepełnosprawności wywołanej dolegliwościami bólowymi kręgosłupa a kolejnością ciąż. W piśmiennictwie istnieje wiele informacji na temat wpływu uczestnictwa kobiet w okresie ciąży w zajęciach oferowanych przez szkoły rodzenia na zmniejszenie dolegliwości bólowych kręgosłupa. Boguszewski i wsp., badający 54 kobiety ciężarne odczuwające dolegliwości bólowe kręgosłupa w odcinku lędźwiowo-krzyżowym, przedstawili wyniki dotyczące wpływu ćwiczeń relaksacyjnych i stabilizacyjnych na zmniejszenie bólu kręgosłupa. Dzięki zastosowaniu wizualno-analogowej skali bólu VAS i kwestionariusza Rolanda-Morrisa po 14 dniach u badanych uczestniczących w zajęciach szkoły rodzenia zaobserwowano pierwsze efekty. Ćwiczenia wpłynęły na zmniejszenie intensywności bólu oraz obniżenie stopnia ograniczenia funkcjonowania w czynnościach życia codziennego spowodowanego

TABELA 5. Ocena stopnia niepełnosprawności u kobiet ciężarnych względem wieku

\begin{tabular}{|c|c|c|c|c|c|}
\hline \multirow{2}{*}{$\begin{array}{c}\text { Stopień } \\
\text { niepełnosprawności }\end{array}$} & \multicolumn{5}{|c|}{ Wiek ankietowanych (w latach) } \\
\hline & $\begin{array}{c}18-25 \\
n(\%)\end{array}$ & $\begin{array}{c}26-30 \\
n(\%)\end{array}$ & $\begin{array}{l}31-35 \\
n(\%)\end{array}$ & $\begin{array}{l}>35 \\
\mathrm{n}(\%)\end{array}$ & $\begin{array}{l}\text { suma } \\
\mathrm{n}(\%)\end{array}$ \\
\hline Niewielka niepełnosprawność & $14(17,29)$ & $11(13,58)$ & & & $25(30,87)$ \\
\hline Mierna niepełnosprawność & & $18(22,22)$ & $24(29,62)$ & $5(6,18)$ & $47(58,02)$ \\
\hline Poważna niepełnosprawność & & & & $5(6,18)$ & $5(6,18)$ \\
\hline Całkowita niepełnosprawność & & & & $1(1,23)$ & $1(1,23)$ \\
\hline Suma & $17(20,99)$ & $29(35,8)$ & $24(29,62)$ & $11(13,59)$ & 81 (100) \\
\hline
\end{tabular}


występującymi dolegliwościami bólowymi kręgosłupa wśród badanych kobiet. Zdaniem autorów korzystne jest więc stosowanie różnego rodzaju aktywności ruchowej podczas ciąży w ramach profilaktyki i leczenia tych przykrych dolegliwości [11]. Nie potwierdzają tego wyniki badań własnych. May i Johnson oceniając wpływ ćwiczeń stabilizacyjnych stosowanych w walce $\mathrm{z}$ dolegliwościami bólowymi kręgosłupa u kobiet w okresie ciąży odnotowali zależność wpływu zastosowania tej terapii na różne rodzaje bólów kręgosłupa. Według nich ból lędźwiowo-krzyżowy odczuwany podczas ciąży jest długotrwały i ma charakter rozlany. Nie odnotowali pozytywnego działania tego rodzaju aktywności podczas ciąży w minimalizacji bólów ostrych [12]. Garshasbi i wsp. grupę kobiet ciężarnych biorących udział w badaniu podzielili na dwie podgrupy. Jedna z nich uczestniczyła w 12-tygodniowych zajęciach ruchowych, a druga nie wykonywała żadnej aktywności ruchowej. Po terapii wśród aktywnych zauważono zmniejszenie intensywności bólu kręgosłupa, natomiast w grupie niećwiczącej odnotowano wzrost intensywności odczuwanego bólu. Autorzy stwierdzili, że najlepsze na zminimalizowanie dolegliwości bólowych kręgosłupa oraz zwiększanie jego ruchomości są ćwiczenia wykonywane w II i III trymestrze ciąży [13].

\section{WNIOSKI}

U większości kobiet ciężarnych zaobserwowano ograniczenia funkcjonalne spowodowane dolegliwościami bólowymi odcinka lędźwiowo-krzyżowego kręgosłupa w stopniu miernym. Stopień ograniczeń zależny jest od trymestru ciąży i kolejności ciąż.

\section{PIŚMIENNICTWO}

1. Boch-Kmieciak J, Cieślik K, Waszak M, Szulc P, Lewandowski J. Zmiany cech somatycznych i krzywizn kręgosłupa u ciężarnych kobiet. Fizjoter Pol 2012;1(4):29-38.

2. Royal College of Obstetricians and Gynaecologists. Ćwiczenia fizyczne kobiet w ciąży. Aktualne (2006 r.) stanowisko Royal College of Obstetricians and Gynaecologists. Med Prakt Ginek Położ 2007;5:13-8.

3. Majchrzycki M, Mrozikiewicz PM, Kocur P, Bartkowiak-Wieczorek J, Hoffmann M, Stryła W, et al. Dolegliwości bólowe dolnego odcinka kręgosłupa u kobiet w ciąży. Ginekol Pol 2010;81:851-5.

4. Simons DG. New views of myofascial trigger points: etiology and diagnosis. Arch Phys Med Rehabil 2008;89(1):157-9.

5. Bartelmus E. Kinezyterapia pozycyjna, oddechowa i techniki sprężystego odkształcania tkanek stosowane podczas pierwszej fazy porodu. Rehabil Prakt 2010;4:24-7.

6. Rogala D. Dolegliwości bólowe w dolnym odcinku kręgosłupa a aktywność fizyczna w czasie ciąży. Pain in the lower part of the spine and physical activity during pregnancy. J Health Sci 2013;3(13):190-205.

7. Rąpała K. Zespoły bólowe kręgosłupa - zagadnienia wybrane. Warszawa: PZWL; 2004. p. 64-100.

8. Bastiaenen CH, de Bie RA, Vlaeyen JW, Goossens ME., Leffers P, Wolters $\mathrm{PM}$, et al. Long-term effectiveness and costs of a brief self-management intervention in women with pregnancy-related low back pain after delivery. BMC Pregnancy Childbirth 2008;8:19.

9. Chityniewicz J, Kulis A. Wpływ aktywności ruchowej i zabiegów masażu na dolegliwości bólowe kręgosłupa lędźwiowego u kobiet w okresie ciąży. Ginek Prakt 2010;2:17-22.

10. Majchrzycki M, Mrozikiewicz PM, Kocur P, Bartkowiak-Wieczorek J, Hoffmann M, Stryła W, et al. Dolegliwości bólowe dolnego odcinka kręgosłupa u kobiet w ciąży. Ginekol Pol 2010;81:851-5.

11. Boguszewski D, Sałata D, Adamczyk JG, Białoszewski D. Ocena skuteczności ćwiczeń relaksacyjnych i stabilizacyjnych w minimalizacji bólu lędźwiowo-krzyżowego odcinka kręgosłupa u kobiet ciężarnych. Med Rev 2014;2:152-61.

12. May S, Johnson R. Stabilization exercises for low back pain a sistematic review. Physiotherapy 2008;94:179-89.

13. Garshasbi A, Faghih Zadeh S. The effect of exercise on the intensity of low back pain in pregnant women. Int J Gynaecol Obstet 2005;88(5):271-5. 